\title{
$\bullet$ Mothers' Attitude Towards Self as a Pre-requisite of Social Competence Skills among Children
}

\author{
IJCRR \\ Section: Healthcare \\ ISI Impact Factor \\ (2019-20): 1.628 \\ IC Value (2019): 90.81 \\ $\operatorname{SJIF}(2020)=7.893$

\section{Smriti Gandhi' ${ }^{1}$, Mamata Mahapatra ${ }^{2}$}

'Research Scholar, Amity lnstitute of Psychology and Allied Sciences, Amity University Uttar Pradesh, Noida, India; ${ }^{2}$ Professor, Amity Institute of Psychology and Allied Sciences, Amity University Uttar Pradesh, Noida, India.

\section{ABSTRACT}

Introduction: With the advancement in society, women have taken up major responsibilities, not just personally but also professionally. The burden of responsibilities brings a lot of stress, some may manage it, but some may become vulnerable to develop various psychological issues like depression, anxiety, etc. The effect of those vulnerabilities can be seen in their personal lives which can affect their children.

Aim: The study focused on assessing the impact of Mothers' attitude towards self that suggests cognitive vulnerabilities towards depression, on their child's Social Competence.

Methodology: The study was carried out on 200 Mothers (working and homemakers) in the age range of 30-50 years and their children with age range 13-18 years. Mothers' attitude was measured using the Attitude Towards Self scale and the child's Social Competence was measured using the Social Competence Scale.

Results: There was a significant difference at $p \leq .01$ in the dimensions of Mothers' Attitude towards Self, namely High Standards $(t= \pm 15.626)$, Self-Criticism ( $t= \pm 8.369)$ and Generalization $(t= \pm 11.203)$, and Social Competence of their children's between working mothers and homemakers $(\mathrm{t}= \pm 20.442)$, where the homemakers and their children were higher on every aspect. The Social Competence between boys and girls $(t= \pm 2.008)$ was also significant at $p \leq .05$, where girls showed higher Social Competence as compared to boys which were calculated using an independent t-test. The relationship between Mothers' negative attitude towards self and their children's social competence, evaluated using Pearson's $r$ correlation, were moderately significant at $p=.01$, however was inversely proportional with a significant impact on the child's social competence showing $49 \%$ of the variance, analyzed using regression.

Conclusion: Therefore, the attitude of working or homemaker mothers significantly affects the child's development.

Key Words: Mothers, Attitude, Cognitive vulnerabilities, Social Competence, Children

\section{INTRODUCTION}

Parents play an important role in nurturing their children that helps them attain developmental milestones. A child learns from the family and especially parents, where both the parents play an equally important role. Mothers' have always been the primary caregivers, as they spend most of the time with the children since the day child opens his/her eyes. ${ }^{1}$ Mother do have to take up multiple roles simultaneously to keep life going, not only hers but for her whole family. For those who choose to work as well, their responsibilities increase substantially, this, in turn, can increase the stress in life. Stress is a very common factor that every individual ex- perience. However, the intensity may vary which can be due to various factors.

Stress can be helpful as it motivates an individual which is also termed as Eustress. It, however, becomes problematic when it starts impacting an individual's life in a negative manner, also known as Distress. ${ }^{2}$ Distress initiates a negative thinking pattern which gradually increases and starts affecting an individual's life and the attitude and perception towards self. It triggers various cognitions that influences negative thinking patterns, also considered as ruminations that become suggestive of self-regulatory vulnerabilities ${ }^{3}$ that may lead to developing various psychological issues, depressive and anxiety symptoms being the most common of all. ${ }^{4}$

\section{Corresponding Author: \\ Smriti Gandhi, House No. 592, Sector-15, Faridabad, Haryana- 121007, India. \\ Telephone: +91-9818888999; Email: smriti_rsethi@yahoo.com}

ISSN: 2231-2196 (Print)

Received: 04.09 .2020

ISSN: 0975-5241 (Online)

Revised: 12.11 .2020

Accepted: 19.02 .2021

Published: 22.06 .2021 
Mothers, with such heavy responsibilities, are becoming vulnerable to all these psychological issues with other stressors in life. ${ }^{5}$ Researchers have shown significant differences in the stress level that may develop cognitive vulnerabilities among working and non-working women as they have more stressful lives as compared to non-working women. ${ }^{6,7,8}$ Their mental well-being either positive or negative, impacts the development of their children, that can be seen in their social and emotional behaviour.

Researchers have identified that the factors that influence the child's social competence are its environment, the attitude of parents, also the employment status of the mothers, as it may reduce the mother-child interaction time which is very important for the child's development. ${ }^{9}, 10$ There may be the negative impact of mother's employment on the child, however, they are still able to engage with their children and impart social and emotional abilities in them. ${ }^{11}$ It may become a problem when mothers have their self-regulatory cognitive vulnerabilities towards developing depressive tendencies and may lead to problems in the social competence of their children as compared to non-working mothers. However, there is a dearth of research on the cognitive vulnerabilities towards psychological issues among women that may create an effect on their children's development. ${ }^{12,13}$

\section{AIM AND OBJECTIVES}

To study the impact of mothers' attitude towards self on the social competence of their children.

The study was carried out with a view of exploring the following objectives:

- To study the difference in the Attitude towards Self between Working Mothers and Homemakers

- To study the difference in the level of Social Competence of the children of Working Mothers and Homemakers

- To study the significant difference in the level of Social Competence between boys and girls

- To examine the relationship between the Mother's Attitude towards Self and their child's Social Competence

- To study the impact of Mother's attitude towards self on their child's Social Competence

\section{HYPOTHESIS}

H1: There is a significant difference in the Attitude towards Self between Working Mothers and Homemakers.

$\mathrm{H} 2$ : There is a significant difference in the level of Social Competence of the children of Working Mothers and Homemakers.
H3: There is a significant difference in the level of Social Competence between boys and girls.

H4: There is a significant relationship between the Mother's Attitude towards Self and their child's Social Competence.

H5: There is a significant impact of a Mother's attitude towards self on their child's Social Competence.

\section{MATERIAL AND METHOD}

\section{Participants}

The questionnaire was distributed among 265 Working Mothers and Homemakers of age range 30-50 years, and their children with age range 13 to 18 years, out which 200 Mothers ( $n=100$ Working Mothers and $n=100$ Homemakers) and their children ( $n=100$ boys and $n=100$ girls) were selected for the study. The remaining 65 participants having clinical depression were not included in the study. The study was approved by the ethical committee and the document is attached in Appendix 1.

\section{Measures}

The cognitive vulnerabilities towards Depression in Mothers was measured using the Attitude Towards Self-Revised scale (ATS-R) which was developed and revised by Carver in the year 2013. ${ }^{12}$ It is a 10 item Likert type scale that evaluates self-regulatory cognitive vulnerabilities towards Depression. It evaluates three core vulnerabilities which are holding overly high standards, being self-critical towards failure and generalizability even from a single failure to a wider sense of self-worth. The reliability coefficient on the dimensions came out to be, for High Standards, Cronbach's Alpha was $\mathrm{r}=.774$, Self-Criticism was $\mathrm{r}=.759$, and for Generalization, the Cronbach's Alpha was $r=.674$. The reliability coefficient suggested moderate to good reliability.

Social Competence in the children was measured by Social Competence Scale developed by Sharma, Shukla \& Shukla in $1992 .{ }^{13}$ It is a 50 item Likert type scale that measures one's social ability and the individual's interpersonal skills, which is evaluated based on 18 dimensions, namely, Social Sensitivity, Social Maturity, Social Skills, Social Relations, Social Commitment, Social Appreciation Ability, Socio-Emotional Integrity, Social Involvement, Social RespectAbility, Social Leadership, Social Cooperation and Compliance, Social Acceptability, Social Tolerance, Social Competition, Social Authority, Adult Resource Exploitability, Social Participation, Pro-Social Attitude and the Composite Score. The reliability of the scale came out to be very high with Cronbach's Alpha $\mathrm{r}=.936$.

\section{Procedure}

Mothers with their children who had come for the Parents Teacher Meeting in a school in Delhi, National Capital Region 
were considered for the study. The responses from two hundred Mothers including their children out of two hundred and sixty-five responses were included in the study according to the inclusion and exclusion criteria. Mothers' attitude towards self was evaluated using a 5-point Likert type scale and their child's social competence was too assessed using another 5-point Likert type scale. The reliability of both the tools was calculated, before the calculation of descriptive and inferential statistics using SPSS v25.

\section{RESULTS}

Mothers suggestive of clinical depression were excluded from the study. The low and moderate scores on the Attitude towards self- Revised scale to study the cognitive vulnerabilities towards depression was considered for further analysis due to the nature of the sample being from a non-clinical population. The results were then analysed using the statistical software SPSS v25.

Table 1 shows the differences between the means of Working Mothers and Homemakers in the Mothers' Attitude towards Self and Social Competence of their children. There was a significant difference in the scores of High Standards of Working Mothers $(\mathrm{M}=7.99, \mathrm{SD}=1.168)$ and Homemakers $(\mathrm{M}=5.44, \mathrm{SD}=1.140) ; \mathrm{t}= \pm 15.626, \mathrm{p} \leq .01$, Self-Criticism of Working Mothers $(\mathrm{M}=7.50, \mathrm{SD}=1.592)$ and Homemakers $(\mathrm{M}=5.63, \mathrm{SD}=1.168) ; \mathrm{t}= \pm 8.369, \mathrm{p} \leq .01$, Generalization of Working Mothers $(\mathrm{M}=9.65, \mathrm{SD}=1.395)$ and Homemakers $(M=9.65, S D=1.395) ; t= \pm 11.203, p \leq .01$, and the Social Competence in the children of Working Mothers $(\mathrm{M}=$ 166.60, $\mathrm{SD}=17.196)$ and Homemakers $(\mathrm{M}=213.31, \mathrm{SD}=$ $15.048) ; \mathrm{t}= \pm 20.442, \mathrm{p} \leq .01$.

An independent sample t-test was conducted to compare Social Competence between Boys and Girls. From Table 2 , it can be gathered that there was a significant difference observed in the scores of Social Competence of Boys $(\mathrm{M}=$ 185.95, $\mathrm{SD}=23.259)$ and Girls $(\mathrm{M}=32.414) ; \mathrm{t}= \pm 2.008, \mathrm{p} \leq$ .05 . The results depicted that girls were high on Social Competence as compared to boys.

Based on the results of the study in Table 3, Mother's High Standards, Self- Criticism and Generalization showed a moderate yet negative correlation with the Social Competence of their children. The correlation values came out to be $-.590,-.417$ and -.606 respectively, which were significant at $\mathrm{p}=0.01$.

Multiple linear regression was calculated to predict Social Competence among children based on their mothers' tendency towards High Standards, Self-Criticism, and Generalization. A significant regression equation was found $(\mathrm{F}(3,196)$ $=62.757, \mathrm{p}=.000$ ), with an $\mathrm{R} 2$ of .490 . The results in Table 4 predicted Social Competence is equal to $282.113-6.027$
(High Standards) - 1.153 (Self- Criticism) - 5.296 (Generalization). Social Competence of children decreased by 6.027 unit of measure for each unit increase in the tendency of High Standards, 1.153 in the tendency to Self-Criticism and 5.296 in the tendency to Generalize among their Mothers. High Standards and Generalization were both statistically significant predictors of Social Competence among their children however, Self- Criticism was not found to be significant.

\section{DISCUSSION}

The current study focused on exploring the differences in the Attitude towards Self between Working Mothers and Homemakers, Social Competence among their children, the difference in the Social Competence of boys and girls. The study also focused on examining if any relationship existed between the Mothers attitude towards self and the Social Competence of their children, and to assess if Mothers' attitude predicted Social Competence in their children.

The Mother's cognitive vulnerabilities were evaluated to study if the tendency for high standards, self-criticism and generalization existed in those who are Working or who are Home Makers. The results showed that these tendencies were higher in Working Mothers as compared with Homemakers which was statistically significant at the $p \leq .01$ level. Researchers in their studies have mentioned that nonworking women have good mental health and low depressive symptoms as compared to working women ${ }^{14}$ which also, in turn, led to decreased satisfaction in life..$^{15}$ Due to work and family pressure, working women were much vulnerable to mental health issues like depression and anxiety, etc. ${ }^{16}$ With this pressure, other problems that were associated with working women were financial issues, workplace problems, higher responsibilities along with multitasking, which was the risk factors linked to depression. ${ }^{17}$ The above factors may have contributed to the mental health of working women which seem to be lower when compared with non-working mothers. These factors may also lead to higher tendencies of Self-criticism in women, which may further play a crucial role in increasing vulnerability towards psychological issues and emotional symptoms. ${ }^{18}$ Mothers' attitude and their mental state affect the development of their children, which was gathered through the data in the present study. The results depicted that working mothers who were vulnerable to depressive tendencies impacted the social competence of their children in a negative way. It was observed that a negative but significant relationship of mothers' negative attitude with the social competence of their children. Children of the working mothers showed low social competence as compared to the children of homemaker mothers. Mothers' negative attitude affects the development of children in a negative manner. ${ }^{19}$ and the negative interactions with the child was negatively correlated with the child's Social Competence. ${ }^{20}$ There also 
existed gender differences in the Social Competence among children. Girls are generally good in the social skills that they possess as compared with boys, further making them more socially competent than boys. The results of the study also showed that girls are higher on social competence as compared to boys, which was also corroborated in the study done by Mohammed Khalifa in 2017. ${ }^{21}$ The study had various limitations which stated that the results of the study were applied to the nuclear family structure and middle economic class of Indian Society. Another limitation stated that as children are already vulnerable in the Adolescent age which can be contributed by various factors that may become a challenge for them, consequently affecting their developmental process, especially social and emotional. Those factors have not been taken into consideration for the study purpose. Despite these limitations, the results of the study can contribute to society. Early detection and managing the stress faced by women irrespective of their employment status may prevent serious mental health issues. These also affect their children. It requires efficient management and balancing of the responsibilities which may lower the risk factors related to developmental issues and further preventing their severity. The outlook may turn out to worsen if other mental illnesses are also present. Identification and essential measures in the initial years of growth and development should primarily be considered for healthy children. Children who may display low scores on social competence have greater chances to develop depression or bipolar disorder or become suicidal. Preventive and positive interventions may be developed for such children. The mental healthcare unit may develop the provisional program to use behavioural modification therapy or talk therapy to help teach children to enable and empower them with skills to deal in day to day life with positive emotions and social behaviour.

\section{CONCLUSION}

Stress can cause various issues in one's life that increases with a wider range of responsibilities that an individual may have. With the change in time, societal norms have also undergone a paradigm shift, where earlier few of the women were working, but now most of them go out for work. They have increased responsibility now, where women must look after their family, with their work. This increased responsibility has increased stress in their life which has further made them more vulnerable to developing psychological issues. Children are impacted directly by the mothers' attitude, this stress negatively changes the mother's attitude, therefore, having a negative impact on the children. The social competence of the children is affected by mothers' attitude towards self and psychological health. Mother being the primary caregiver irrespective of employment or otherwise is the crucial nurturer of holistic development of their children.
This will support in creating good human values and healthy communities at large.

\section{ACKNOWLEDGEMENT}

The authors acknowledge the immense help received from the scholars whose articles are cited and included in references of this manuscript. The authors are also grateful to authors/editors/publishers of all those articles, journals, and books from where the literature for this article has been reviewed and discussed.

\section{Conflict of Interest}

NIL

\section{Source of Funding}

NIL

\section{REFERENCES}

1. Singh K. To Measure the Role of Mother's Acquaintance Concerning Their Kid's Health. Int J Curr Res Rev. 2021;13(02):5154.

2. Bienertova V J, Lenart P, Scheringer M. Eustress and Distress: Neither Good Nor Bad, but Rather the Same?. BioEssays. 2020;42(7):1900238.

3. Carver C, Ganellen R. Depression and components of self-punitiveness: High standards, self-criticism, and overgeneralization J Abn Psych. 1983;92(3):330-337.

4. Donaldson C, Lam D, Mathews A. Rumination and attention in major depression. Beh Res Ther. 2007;45(11):2664-2678.

5. M J. Depression and Women [Internet]. Psych Central. 2020 [cited 31 January 2021]. Available from: https://psychcentral. com/lib/depression-and-women/.

6. Ahrens C, Ryff C. Multiple Roles and Well-being: Sociodemographic and Psychological Moderators. Sex Roles. 2006;55(1112):801-815.

7. Alex R. Stress tolerance and adjustment among working and non-working women: A comparative study. Journal of Research: The Bede Athen. 2015;6(1):7.

8. Singh S.K. Life Satisfaction and Stress Level among Working and Non-Working Women. Int J Ind Psych. 2014;1(4).

9. Del BD, Vuri D. The mismatch between employment and child care in Italy: the impact of rationing. J Pop Econ. 2007;20(4):805832.

10. Fitzpatrick M. Starting School at Four: The Effect of Universal Pre-Kindergarten on Children's Academic Achievement. J Econ Anal Pol. 2008;8(1).

11. Sultana A, Noor Z. Mothers' Perception on the Impact of Employment on their Children: Working and Non-working Mothers. Int J Soc Sci. 2012;2(1).

12. Carver C. Attitudes Toward Self (ATS) | Measurement Instrument Database for the Social Sciences [Internet]. Midss.org. 2021 [cited 31 January 2021]. Available from: https://www. midss.org/content/attitudes-toward-self-ats.

13. Sharma V, Shukla P, Shukla K. Manual for Social Competence Scale. 1992.

14. Vaghela K. Mental Health of Working and Non-Working Women in Ahmadabad. Int J Ind Psych. 2014;1(4). 
15. Mavric B, Alp Z, Kunt A. Depression and Life Satisfaction among Employed and Unemployed Married Woman in Turkey: A Gender-Based Research Conducted in a Traditional Society. Inju J. 2017;2(2).

16. Dibaji S, Oreyzi RS, Abedi M. Occupation or Home: Comparison Housewives and Working Women in the Variables of Stress, Depression and Perception of Quantitative, Mental and Emotional Home Demands. Rev Europ Stud. 2017;9(2):268.

17. Balaji A., Sarumathi V., Saranya N. A comparative study on Depression among Working and Non- Working Women in Chennai, Tamil Nadu, India. Research and Reviews. J Med Heal Sci. 2014;3(1):73-76.
18. Özer E. The Impact of Core Self-evaluation on Self-criticism. Univ J Edu Res. 2019;7(7):1526-1531.

19. Dhingra V, Keswani S. Impact of Working and Non - Working Mothers on Development of their Children in Madhya Pradesh. Int J Res Adv Techn. 2019;7(3):1369-1375.

20. Attili G, Vermigli P, Roazzi A. Children's Social Competence, Peer Status, and the Quality of Mother- Child and Father-Child Relationships. Eur Psych. 2010;15(1):23-33.

21. Khalifa M. Towards Mental Health with Child Social Competence and Parental Disciplinary Approaches in Egypt. Int J Appl Psych. 2017;7(3):60-69.

Table 1: Mean Scores, SD and differences between the means of Working Mothers and Homemakers in the Mothers Attitude towards Self and Social Competence of their children

\begin{tabular}{|c|c|c|c|c|c|}
\hline \multicolumn{6}{|c|}{ Group Statistics } \\
\hline & MOTHERS & $\mathbf{N}$ & Mean & Std. Deviation & Std. Error Mean \\
\hline \multirow{2}{*}{ High Standards } & Working & 100 & $7 \cdot 990$ & 1.1677 & .1168 \\
\hline & Home Makers & 100 & $5 \cdot 440$ & 1.1399 & .1140 \\
\hline \multirow[t]{2}{*}{ Self-Criticism } & Working & 100 & $7 \cdot 500$ & 1.5923 & .1592 \\
\hline & Home Makers & 100 & 5.630 & 1.5677 & .1568 \\
\hline \multirow[t]{2}{*}{ Generalization } & Working & 100 & 9.650 & 1.3953 & .1395 \\
\hline & Home Makers & 100 & 7.010 & 1.8989 & 1899 \\
\hline \multirow[t]{2}{*}{ Social Competence } & Working & 100 & 166.600 & 17.1958 & 1.7196 \\
\hline & Home Makers & 100 & 213.310 & 15.0479 & 1.5048 \\
\hline
\end{tabular}

\begin{tabular}{lcccc} 
& \multicolumn{2}{c}{ Independent Samples Test } & & \\
& t-test for Equality of Means & df & Sig. (2-tailed) \\
High Standards & $\mathbf{t}$ & 15.626 & 198 & $.000^{*}$ \\
Self-Criticism & 8.369 & 198 & $.000^{*}$ \\
Generalization & 11.203 & 198 & $.000^{*}$ \\
Social Competence & -20.442 & 198 & $.000^{*}$ \\
\hline
\end{tabular}

Table 2: Differences in Mean Scores in Social Competence between the Boys and Girls

\begin{tabular}{|c|c|c|c|c|c|}
\hline \multicolumn{6}{|c|}{ Group Statistics } \\
\hline & Children's Gender & $\mathbf{N}$ & Mean & Std. Deviation & Std. Error Mean \\
\hline \multirow[t]{2}{*}{ Social Competence } & Boys & 100 & 185.950 & 23.2594 & 2.3259 \\
\hline & Girls & 100 & 193.960 & 32.4140 & 3.2414 \\
\hline
\end{tabular}

\begin{tabular}{|c|c|c|c|}
\hline \multicolumn{4}{|c|}{ Independent Samples test } \\
\hline & \multicolumn{3}{|c|}{ t-test for Equality of Means } \\
\hline & $\mathbf{t}$ & df & Sig. (2-tailed) \\
\hline Social Competence & -2.008 & 198 & $.046^{*}$ \\
\hline
\end{tabular}


Table 3: Relationship between Mothers' Attitude towards Self and Social Competence of their Children

\begin{tabular}{lcccc} 
& High Standards & Self-Criticism & Generalization & Social Competence \\
High Standards & 1 & & & \\
Self-Criticism & $0.526^{* *}$ & 1 & 1 & \\
Generalization & $0.470^{* * *}$ & $0.517^{* *}$ & $-.0606^{* *}$ & 1 \\
Social Competence & $-0.590^{* *}$ & $-0.471^{* *}$ & \\
\hline
\end{tabular}

**. Correlation is significant at the o.o1 level (2-tailed).

Table 4 (A, B and C): Regression Analysis of Dimensions of Mothers' Attitude towards Self on Social Competence of their Children

\begin{tabular}{lcccc}
$\begin{array}{l}\text { A. Model Summary } \\
\text { Model }\end{array}$ & R & R Square & Adjusted R Square & Std. Error of the Estimate \\
1 & $.700^{\mathrm{a}}$ & .490 & .482 & 20.4551 \\
\hline
\end{tabular}

a. Predictors: (Constant), Generalization, High Standards, Self-Criticism

\begin{tabular}{lllllll}
$\begin{array}{l}\text { B. ANOVA } \\
\text { Model }\end{array}$ & & Sum of Squares & df & Mean Square & F & Sig. \\
1 & Regression & 78774.196 & 3 & 26258.065 & 62.757 &. .ooo $^{\mathrm{b}}$ \\
& Residual & 82008.399 & 196 & 418.410 & & \\
& Total & 160782.595 & 199 & & & \\
\hline
\end{tabular}

a. Dependent Variable: Social Competence

b. Predictors: (Constant), Generalization, High Standards, Self-Criticism

\begin{tabular}{|c|c|c|c|c|c|c|}
\hline \multicolumn{7}{|c|}{ C. Coefficients } \\
\hline \multirow{2}{*}{\multicolumn{2}{|c|}{ Model }} & \multicolumn{2}{|c|}{ Unstandardized Coefficients } & \multirow{2}{*}{$\begin{array}{c}\text { Standardized Coefficients } \\
\text { Beta }\end{array}$} & \multirow[t]{2}{*}{$\mathbf{t}$} & \multirow[t]{2}{*}{ Sig. } \\
\hline & & B & Std. Error & & & \\
\hline \multirow[t]{4}{*}{1} & (Constant) & 282.113 & 6.931 & & 40.703 & .000 \\
\hline & High Standards & -6.027 & 1.030 & -.365 & -5.851 & .000 \\
\hline & Self-Criticism & -1.153 & .996 & -.074 & -1.157 & .249 \\
\hline & Generalization & -5.296 & .829 & -.396 & -6.392 & .000 \\
\hline
\end{tabular}

a. Dependent Variable: Social Competence 